\title{
Comparative Analysis of Direct and Indirect Methods for the Determination of Maximal Oxygen Uptake in Sedentary Young Adults
}

\author{
Alfredo Moreira da Rocha Neto, ${ }^{3(0)}$ Artur Haddad Herdy, ${ }^{1,2}$ Pablo de Souza $^{1,2}$ \\ Instituto de Cardiologia de Santa Catarina, ${ }^{1}$ Florianópolis, SC - Brazil \\ Clínica Cardiosport, ${ }^{2}$ Florianópolis, SC - Brazil \\ Hemovida - Instituto de Intervenção Cardiovascular, ${ }^{3}$ Campo Grande, MS - Brazil
}

\section{Abstract}

Background: Maximal oxygen uptake is a powerful prognostic indicator and a reliable measure of physical conditioning. It can be measured directly by cardiopulmonary exercise testing (CPET) or indirectly by formulas derived from conventional protocols.

Objective: We compared the $\mathrm{VO}_{2}$ max obtained by formula using exercise testing with Bruce protocol (BP) with the $\mathrm{VO}_{2}$ max obtained by CPET on the treadmill.

Methods: We selected 41 healthy, non-obese, physically inactive young volunteers, aged between 21 and 50 years, residents of Florianópolis, Brazil.

Results: Twenty-one women $(52 \%)$ with mean age of $35.62 \pm 8.83$ years, and 20 males, with mean age of 32.5 \pm 7.18 years participated in the study. Statistically significant differences were found for $\mathrm{VO}_{2}$ max between the two methods (BP $-42.31 \pm 5.21 \mathrm{ml} / \mathrm{kg}$.min vs. CPET $-30.46 \pm 5.50 \mathrm{ml} / \mathrm{kg} . \mathrm{min} ., \mathrm{p}<0.0001$ ). The Bruce formula overestimated the result by $34.1 \%$ (BP $-45.95 \pm 3.94 \mathrm{ml} / \mathrm{kg} . \mathrm{min}$ vs. CPX $-34.27 \pm 4.20 \mathrm{ml} / \mathrm{kg} . \mathrm{min}, \mathrm{p}<0.0001$ ) for men, and by $44.8 \%$ (BP $-38.84 \pm 3.72 \mathrm{ml} / \mathrm{kg} . \mathrm{min}$ vs. CPX $-26.83 \pm 3.90, \mathrm{p}<0.0001$ ) for women. A moderate correlation was observed between the methods $(\mathrm{r}=0.65)$. When classifying the results according to the table of aerobic capacity of the American Heart Association, the agreement was null (kappa =0.0034; Pearson chi2 = 0.001).

Conclusion: $\mathrm{VO}_{2}$ estimated by $\mathrm{BP}$ is not capable of demonstrating the true aerobic capacity in these individuals, while CPET is an important tool for early detection of diminished functional capacity in sedentary young men and women. (Int J Cardiovasc Sci. 2019;32(4):362-367)

Keywords: Cardiovascular Diseases; Exercise Test; Oxygen Consumption; Adolescent; Physical Fitness; Sedentarism.

Maximal oxygen uptake is a powerful prognostic indicator and a reliable measure of physical conditioning. It can be measured directly by cardiopulmonary exercise testing (CPET) or indirectly by formulas derived from conventional protocols. We compared the $\mathrm{VO}_{2} \max$ obtained by formula using exercise testing with Bruce protocol (BP) with the $\mathrm{VO}_{2}$ max obtained by CPET on the treadmill. We selected 41 healthy, non-obese, physically inactive young volunteers, aged between 21 and 50 years, residents of Florianópolis, Brazil. Twenty-one women $(52 \%)$ with mean age of $35.62 \pm 8.83$ years, and 20 males, with mean age of $32.5 \pm 7.18$ years participated in the 
study. Statistically significant differences were found for $\mathrm{VO}_{2}$ max between the two methods (BP $-42.31 \pm 5.21 \mathrm{ml}$ / kg.min vs. CPET - $30.46 \pm 5.50$ ml / kg.min., p < 0.0001). The Bruce formula overestimated the result by $34.1 \%$ (BP - $45.95 \pm 3.94 \mathrm{ml} / \mathrm{kg}$.min vs. CPX $-34.27 \pm 4.20 \mathrm{ml} /$ kg.min, $\mathrm{p}<0.0001$ ) for men, and by $44.8 \%$ (BP $-38.84 \pm$ $3.72 \mathrm{ml} / \mathrm{kg}$.min vs. CPX $-26.83 \pm 3.90, \mathrm{p}<0.0001$ ) for women. A moderate correlation was observed between the methods $(r=0.65)$. When classifying the results according to the table of aerobic capacity of the American Heart Association, the agreement was null (kappa = 0.0034; Pearson chi2 $=0.001$ ). Conclusion: $\mathrm{VO}_{2}$ estimated by $\mathrm{BP}$ is not capable of demonstrating the true aerobic capacity in these individuals, while CPET is an important tool for early detection of diminished functional capacity in sedentary young men and women.

\section{Introduction}

Maximal oxygen uptake $\left(\mathrm{VO}_{2} \max \right)$ is the product of the arteriovenous oxygen difference and cardiac output. ${ }^{1,2}$ It is the most important physiological measurement in defining functional capacity of an individual (aerobic power). ${ }^{3} \mathrm{VO}_{2}$ max varies with body weight, age, physical activity level and presence of cardiorespiratory disease. ${ }^{1,4,5}$ The parameter is used to prescribe exercise, evaluate the effects of training and therapeutic interventions, and as a risk stratification tool for the occurrence of cardiovascular disease. ${ }^{3,6} \mathrm{VO}_{2}$ max can be directly measured by analysis of breathing gases during cardiopulmonary exercise testing (CPET) or estimated by the stress test using

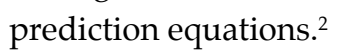

Physical fitness has been shown in several studies to be an important predictor of all-cause and cardiovascular mortality. ${ }^{7-12}$ On the other hand, a sedentary lifestyle is an important cardiovascular risk factor, with increasing prevalence in the world population..$^{13}$ The Bruce protocol (BP) is the main non-invasive method for cardiovascular assessment performed in asymptomatic individuals. ${ }^{14}$ However, functional capacity estimated by formulas during the test may be inaccurate for physically inactive young individuals, leading to a wrong assessment of fitness and minimizing the real cardiovascular risk posed by a low physical fitness, commonly seen in these individuals.

Aiming at evaluating the difference in functional capacity between the direct and indirect method in inactive young individuals, $\mathrm{VO}_{2}$ max was measured by the CPET and the BP formulas.

\section{Methods}

Fifty healthy, non-obese and physically active individuals were invited to participate in the study. All were residents of Florianópolis city, Brazil. Nine individuals declined to participate, and 41 were then included. Participants were randomly assigned to CPET on a treadmill (Inbramed ${ }^{\circledR} 1999$, Brazil), with ramp protocol (ErgoPC Elite version 3.3.6.2, 1999, Micromed $^{\circledR}$, Brazil) and gas analyzer (Metalyzer ${ }^{\circledR}, 2004$, Germany) or to the BP (ErgoPC13 version 2.4.8.5, 1998, Micromed ${ }^{\circledR}$, Brazil), with a 48 interval between the tests. The formula used to estimate $\mathrm{VO}_{2}$ by the $\mathrm{BP}$ was the one available in the most popular ergometry software in Brazil: physically inactive men $-\mathrm{VO}_{2}=(\mathrm{TIME}(\mathrm{min}) \times 2.9)+8.33$. Women $-\mathrm{VO}_{2}=($ TIME $(\mathrm{min}) \times 2.74)+8.03 .{ }^{1}$ The estimated predicted $\mathrm{VO}_{2}$ for each individual was estimate by the formulas (mL/Kg.min):3,5

- Men: $\mathrm{VO}_{2}=60-0.55 \mathrm{x}$ age (years);

- Women: $\mathrm{VO}_{2}=48-0.37 \times$ age (years).

All tests were performed by an experienced cardiologist, qualified to perform ergometric test and CPET. Treadmill tests were carried out following the Brazilian Society of Cardiology guidelines on ergometric and cardiopulmonary tests. ${ }^{3} \mathrm{VO}_{2}$ max was considered as the highest $\mathrm{VO}_{2}$ reached during stress $\left(\mathrm{VO}_{2}\right.$ peak). After direct or indirect measurement of $\mathrm{VO}_{2^{\prime}}$ participants were classified by cardiorespiratory fitness using the American Heart Association table and grouped into four groups - low, moderate, high and very high. ${ }^{5}$ All participants signed the informed consent form and the study protocol was approved by the ethics committee of the institution.

Statistical analysis was performed using the Stata SE 9 and the Microsoft Excel software. The Student's t-test was used to compare means between matched samples. Correlation was analyzed by Pearson correlation. Agreements were analyzed using weighted kappa statistic. A $p \leq 0.05$ was set as statistically significant.

\section{Results}

Twenty-one (52\%) of the 41 individuals included were women. Mean age was $34.1 \pm 8.12$, varying from 21 to 50 years. Mean body mass index (BMI) was $24.5 \mathrm{Kg} / \mathrm{m}^{2} \pm$ 3.34 , and mean weight and height was $72.8 \pm 15.7 \mathrm{~kg}$ and $1.73 \pm 0.11 \mathrm{~m}$, respectively. Mean $\mathrm{VO}_{2}$ max was $42.31 \pm$ $5.21 \mathrm{~mL} / \mathrm{Kg}$.min for the BP and $30.46 \pm 5.50 \mathrm{~mL} / \mathrm{Kg}$.min for the CPET with ramp protocol, $\mathrm{p}<0.0001$. Analysis by sex (Figure 1) revealed significant difference between 
$\mathrm{VO}_{2}$ max estimated by the BP and the CPET $(38.85 \pm 3.72$ $\mathrm{mL} / \mathrm{Kg}$.min versus $26.83 \pm 3.90 \mathrm{~mL} / \mathrm{Kg}$.min, respectively, $\mathrm{p}<0.0001)$ for women, and for men $(45.94 \pm 3.94 \mathrm{~mL} /$ Kg.min versus BP $34.26 \pm 4.21 \mathrm{~mL} / \mathrm{Kg}$.min, respectively, $\mathrm{p}<0.0001$ ) The BP overestimated $\mathrm{VO}_{2}$ max by $44.8 \%$ for women and by $34.1 \%$ for men compared with the CPET.

No difference was found in maximal effort, measured by maximal heart rate (HRmax) between the tests. During the BP and CPET, HR max was $184.8 \pm 9.47$ vs $183.1 \pm$ 10.03 , respectively, for men, and $179.8 \pm 11.68$ versus 180.8 \pm 12.63 , respectively, for women, $p=N S$ ).

There was a moderate correlation between the two methods $(r=0.65)$, and the agreement between the tests regarding cardiorespiratory fitness was null (Figure 2) $($ Kappa $=0.0034$ and chi-square $=0.001)$. Most participants showed high or very high cardiorespiratory fitness by the BP and moderate or low cardiorespiratory fitness according to the CPET.

\section{Discussion}

Cardiorespiratory fitness has been shown to be an important prognostic marker of morbidity and mortality in young, older, healthy individuals with heart diseases. ${ }^{8,15,16}$ Most studies have classified individuals according to their performance in ergometric tests. In Brazil and in the USA, the ergometric test on the treadmill has been widely used, and the $\mathrm{BP}$ is the main test performed. ${ }^{14}$

Although individual risk to stress tests may be stratified by test duration, functional capacity may be overestimated in young adults, even in physically inactive ones. In this regard, when age range is used for risk stratification, conventional stress test is not an accurate test to evaluate functional capacity. Sedentary habits have long-term, cumulative effects, and several studies have shown that it is never too late to decrease the risk by improving physical fitness.

In most computer programs for exercise stress testing in Brazil, $\mathrm{VO}_{2}$ is estimated using the $\mathrm{BP}$ formula, and used to classify subjects according to cardiorespiratory fitness. Our study showed an important overestimation of the indirect assessment of $\mathrm{VO}_{2}$ by the BP.

In 1973, Bruce et al., ${ }^{1}$ studied 295 physically active or inactive adults by exercise testing on the treadmill, and direct analysis of gases, from which derived the formulas currently used. Ong et al., ${ }^{4}$ measured $\mathrm{VO}_{2}$ max by CPET and compared it with that obtained by cycle ergometer test (prediction equations). The formulas overestimated the results by $13.74 \%$ for men and $10.55 \%$ form women. ${ }^{4}$ Fairbarn et al., ${ }^{17}$ evaluated 231 non-athletes aged from

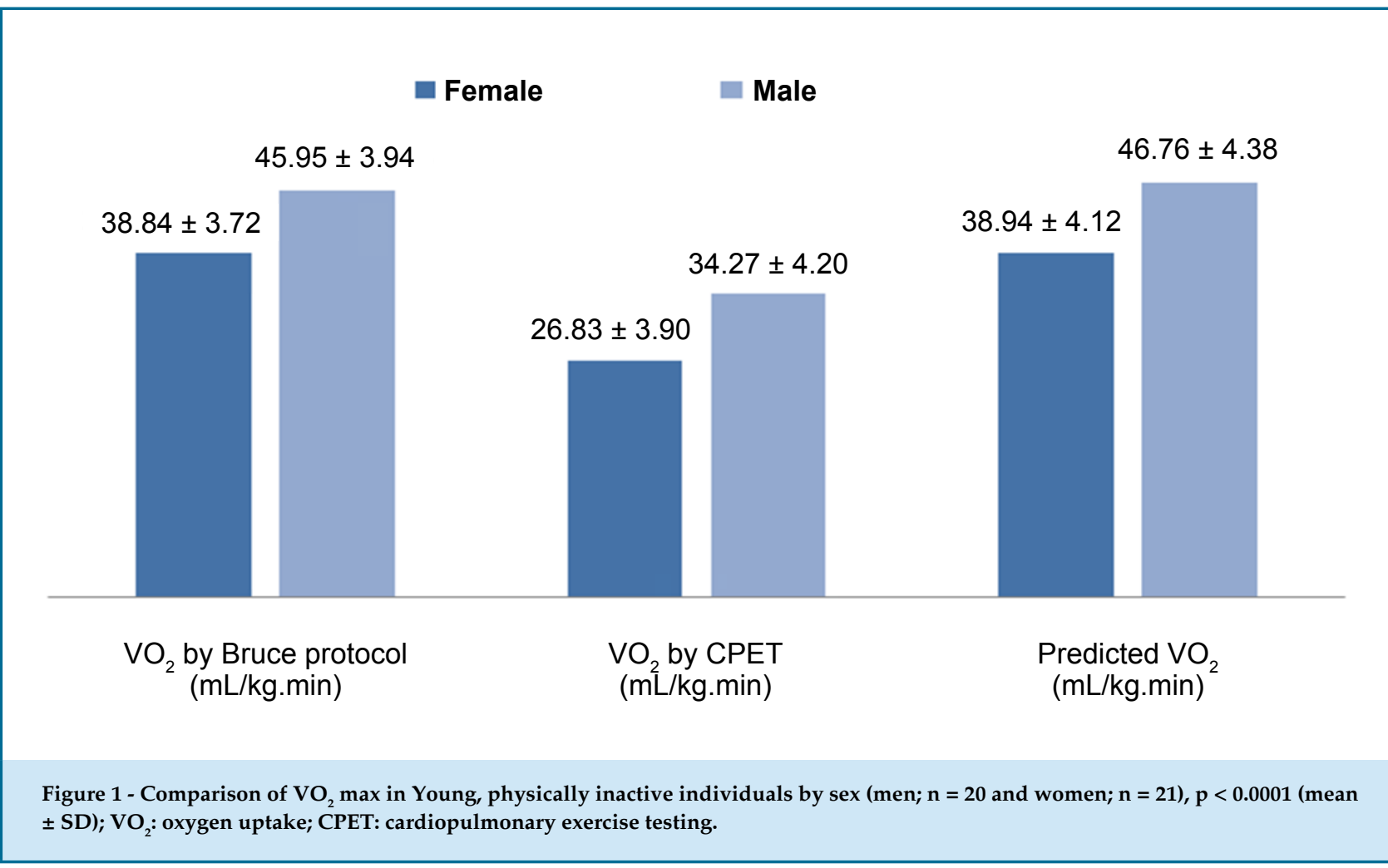




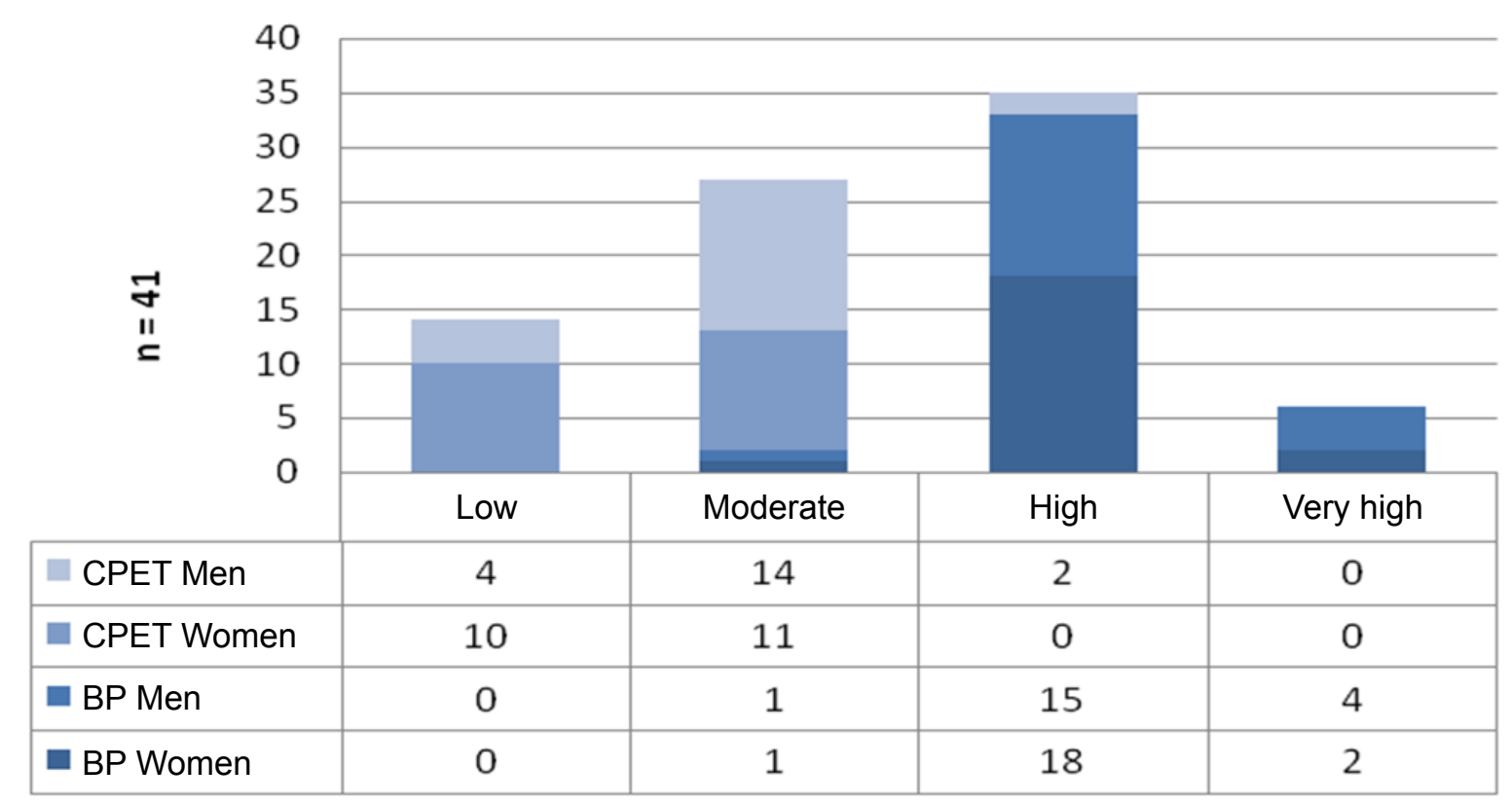

Figure 2 - Null hypothesis of agreement between the methods (Kappa $\left.=0.0034 ; \mathrm{chi}^{2}=0.001 ; \mathrm{p}=0.3713\right)$ based on the American Heart Association classification of the aerobic capacity; CPET: cardiopulmonary exercise testing; BP: Bruce protocol.

20 to 80 years by cycle ergometer test and found a difference in $\mathrm{VO}_{2}$ max measured by the equations of $36.17 \%$ and $26.47 \%$ for men and women, respectively, with higher values obtained by the equations. ${ }^{17}$ Neder et al., ${ }^{18}$ conducted a study with 120 physically inactive volunteers and observed an increment in $\mathrm{VO}_{2}$ by $14.71 \%$ among men and $22.29 \%$ among women. Most studies have used the cycle ergometer test for this comparison, and reported $\mathrm{VO}_{2}$ values $5-11 \%$ lower than those obtained from treadmill tests. However, in the American continent, the treadmill exercise test is the most commonly performed, mainly the BP..$^{19} \mathrm{In}$ our study sample, results obtained from the treadmill test were even higher, maybe because we have used a treadmill ergometer. Similar to our study, Fairbam et al., ${ }^{17}$ also reported the biggest differences in $\mathrm{VO}_{2}$ max among men, although they used an ergometer cycle to assess aerobic capacity. In a nation-wide Brazilian study published in 2011, Peserico et al., ${ }^{20}$ assessed aerobic capacity in trained female runners, by measuring $\mathrm{VO}_{2}$ max both by direct method and indirectly by Foster's formula (1996) using a treadmill ergometer. The authors found that $\mathrm{VO}_{2}$ was significantly underestimated when estimated by the prediction formula as compared with direct analysis of gases, indicating substantial limitations of the approach in determining functional capacity in these individuals. ${ }^{20}$ Most of previous studies reported contrasting results, showing an overestimation of the $\mathrm{VO}_{2}$ max indirectly estimated by regression and conventional ergometer test, regardless of the protocol and type of ergometer used. ${ }^{21,22}$ Also, according to Santos ${ }^{21}$ and Rondon et al., ${ }^{22}$ the results of $\mathrm{VO}_{2} \max$ obtained by indirect measurement are influenced by cardiorespiratory fitness of the study subjects. In these studies, greater $\mathrm{VO}_{2}$ max values, estimated by the ACSM formula, were higher in individuals with poor cardiorespiratory fitness than in those with moderate fitness. These findings suggest that both the type of exercise test protocol and the type of prediction formulas may affect $\mathrm{VO}_{2}$ estimation, by either overestimating or underestimating the true values. Our study was the first to perform treadmill ergometer exercise test in a group composed of both men and women, young and older subjects, physically active and inactive individuals for a comparative analysis of $\mathrm{VO}_{2}$ max directly measured by CPET with that estimated by formulas.

$\mathrm{VO}_{2}$ prediction equations derive from studies conducted in North America and Europe. Thus, the results may not be extended to other populations, as pointed by Ong et al., ${ }^{15}$ The formula used in the $\mathrm{BP}^{1}$ was 
developed in a North American population in the 70's. When applied to the Brazilian population, the formula was found to overestimate $\mathrm{VO}_{2}$ max values. According to Neder et al., ${ }^{18}$ this difference is common in studies using prediction equations for $\mathrm{VO}_{2}$ max. We have recently published reference values for CPET in our population, ${ }^{23}$ and a direct and unequivocal measurement of $\mathrm{VO}_{2}$ gives us the chance to evaluate actual cardiorespiratory fitness of each individual by sex and age range.

The fact that the tests were performed on different days, using different protocols (Bruce versus ramp) may have been a limitation of this study. However, the hemodynamic parameters obtained from the tests were not significantly different, allowing us to infer that there was a similar cardiorespiratory and physical performance by the subjects in both tests. In the present study, we found a significant discrepancy in the classification of cardiorespiratory fitness by the AHA and by the $\mathrm{VO}_{2}$ prediction formulas. The $\mathrm{BP}$ is more widely used for $\mathrm{VO}_{2}$ calculation in clinical practice in Brazil than spiroergometric tests. Therefore, a possible overestimation of $\mathrm{VO}_{2}$ values by the BP results in an erroneous evaluation of the cardiorespiratory fitness of the individuals. This, in turn, may represent a lack of opportunity to advise young individuals about the negative effects of a sedentary lifestyle and a low cardiorespiratory capacity.

\section{Conclusion}

The assessment of aerobic capacity is an important risk stratification tool in young, physically inactive subjects. Prediction formulas of $\mathrm{VO}_{2}$ max, derived from cycle or treadmill exercise tests using the $\mathrm{BP}$, are not able to reproduce the true cardiorespiratory capacity

\section{References}

1. Bruce AR, Kusumi F, Hosmer, D. Fundamentals of clinical cardiology. Am Heart J. 1973;85(4):546-62.

2. Carreira MA. Fisiologia do Exercício. In: Ergometria: ergoespirometria, cintilografia e ecocardiografia de esforço. Costa RV \& Carreira MA. Ed. Rio de Janeiro: Atheneu;2007.

3. Meneghelo RS, Araujo CG, Stein R, Mastrocolla LE, Albuquerque PF, Serra SM, et al. Sociedade Brasileira de Cardiologia. III Diretrizes da Sociedade Brasileira de Cardiologia sobre Teste Ergométrico. Arq Bras Cardiol. 2010;95(5 Suppl 1):1-26

4. Ong KC, Loo CM, Ong YY, Chan SP, Earnest A, Saw SM. Predictive values for cardiopulmonary exercise testing in sedentary Chinese adults. Respirology. 2002;7(3):225-31. in this population, overestimating it. The present study draws attention to the need for an accurate measurement of fitness in this group by CPET, aiming at enabling early warning of these individuals about the risks of a sedentary lifestyle.

\section{Author contributions}

Conception and design of the research: Rocha Neto AM, Herdy AH. Acquisition of data: Rocha Neto AM, Herdy AH, Souza P. Analysis and interpretation of the data: Rocha Neto AM, Herdy AH, Souza P. Statistical analysis: Rocha Neto AM, Herdy AH, Souza P. Obtaining financing: Rocha Neto AM. Writing of the manuscript: Rocha Neto AM, Souza P. Critical revision of the manuscript for intellectual content: Rocha Neto AM, Souza P.

\section{Potential Conflict of Interest}

No potential conflict of interest relevant to this article was reported.

\section{Sources of Funding}

There were no external funding sources for this study.

\section{Study Association}

This study is not associated with any thesis or dissertation work.

\section{Ethics approval and consent to participate}

This article does not contain any studies with human participants or animals performed by any of the authors.
5. Froelicher VF ; Myers JN. Exercise and the heart. Philadelphia: Saunders;2000.

6. Rodrigues AN, Peres AJ, Carletti L, Bissoli NS, Abreu GR. Maximum oxygen uptake in adolescents as measured by cardiopulmonary exercise testing: a classification proposal . J Pediatr (Rio J). 2006;82(6):426-30.

7. Wei M, Kampert JB, Barlow CE, Nicaman MZ, Gibbons LW, Paffenbarger RS, et al. Relationship between low cardiorespiratory fitness and mortality in normal-weigth, overweigth and obese men. JAMA. 1999;282(16):1547-53

8. Myers J, Prakash M, Froelicher V, Do D, Partington S, Atwood E. Exercise capacity and mortality among men referred for execise testing. $\mathrm{N}$ Engl J Med. 2002;346(11):793-801 
9. Sesso HD, Paffenbarger RS, Lee IM. Physical activity and coronary heart disease in men: The Harvard Alumni Study. Circulation. 2000;102(9):975-80.

10. Kokkinos P, Myers J, Kokkinos JP, Pittaras A, Narayan P, Manolis A, et al. Exercise capacity and mortality in black and white men. Circulation. 2008;117(5):614-22.

11. Lee IM, Paffenbarger RS. Associations of ligth, moderate and vigorous intensity physical activity with longevity: The Harvard Alumni Health Study. Am J Epidemiol. 2000;151(3):293-9.

12. Myers J, Gullestad L, Vagelos R, Do D, Bellin D, Ross H, Fowler MB Cardiopulmonary exercise testing and prognosis in severe heart failure: $14 \mathrm{ml} / \mathrm{Kg} / \mathrm{min}$ revisited. Am Heart J. 2000;139( 1 Pt 1):78-84.

13. Yusuf S, Hawken S, Ounpuu S, Dans T, Avezum A, Lanas F, et al Effect of potentially modifiable risk factors associated with myocardial infarction in 52 countries (the INTERHEART study): case-control study. Lancet. 2004;364(9438):937-52.

14. Myers J, Bellin D. Ramp exercise protocols for clinical and cardiopulmonary exercise testing. Sports Med. 2000;30(1):23-29.

15. Katzmarzih PT, Curch TS, Blair SN. Cardiorrespiratory fitness attenuates the effects of the metabolic syndrome on all-cause and cardiovascular disease mortality in men. Arch Intern Med. 2004;164(10):1092-97

16. Mancini DM, Eisen H, Kussmaul W, Mull R, Edmunds Jr LH, Wilson JR. Value of peak exercise oxygen consumption for optimal timing of cardiac transplantation in ambulatory patients with heart failure. Circulation. 1991;83(3):778-86
17. Fairbarn MS, Blackie SP, McElvaney NG, Wiggs BR, Paré PD, Pardy RL. Prediction of heart rate and oxygen uptake during incremental and maximal exercise in healthy adults. Chest. 1994; 105(5):1365-9.

18. Neder JA, Nery LE, Castelo A, Andreoni S, Lerario MC, Sachs A, et al. Prediction of metabolic and cardiopulmonary responses to maximum cycle ergometry: a randomised study. Eur Respir J. 1999;14(6):1304-13.

19. Wasserman K, Hansen JE, Sue DV, Whipp BJ. Principles of exercise testing and interpretation. Philadelphia: Lea and Febiger;1987.

20. Segabinazi PC, Mezzaroba PV, Nogueira GA, Moraes SM, Machado FA. Comparação entre os métodos direto e indireto de determinação do consumo máximo de oxigênio em mulheres corredoras. Rev Bras Med Esporte. 2011;17(4):270-3.

21. Santos MA. Análise da prescrição e da aplicabilidade do consumo de oxigênio de reserva durante o exercício aeróbio contínuo nas intensidades de $50 \%$ a $80 \%$ do consumo máximo de oxigênio. [Tese]. Espírito Santo: Universidade Federal do Espírito Santo( UFES);2007.

22. Rondon MU, Forjaz CL, Nunes N, Amaral SL, Barretto AC, Negrão AL. Comparação entre a prescrição de intensidade de treinamento físico baseado na avaliação ergométrica convencional e na ergoespirométrica. Arq Bras Cardiol. 1998;70(3):159-66.

23. Herdy $\mathrm{AH}$, Uhlendorf D. Reference values for cardiopulmonary exercise testing for sedentary and active men and women. Arq Bras Cardiol. 2011;96(1):54-9. 